\section{Variabilidad de las precipitaciones y sus efectos sobre la respuesta espacio-temporal de cuerpos de agua en la Región Pampeana, Argentina}

Tesis de Especialización en Teledetección y Sistemas de Información Geográfica aplicados al estudio del medio ambiente.

Autores: Federico Ferrelli y

Vanina Solange Aliaga

Directora: Dra. Vanesa Yael Bohn

Defensa Pública: diciembre de 2015.

DOI: http://dx.doi.org/10.19137/huellas-2016-2015

Las precipitaciones constituyen uno de los principales ingresos de agua al balance hídrico de una región o sistema natural. La variabilidad de éstas ocasiona en muchos casos inundaciones o sequías severas que pueden afectar a la población, sus actividades económicas, el acceso al agua potable y las coberturas del suelo. El surgimiento de los Sistemas de Información Geográfica (SIG) facilitó el análisis de grandes volúmenes de datos y posibilitósu estudio de forma espaciotemporal. Por otro lado, el desarrollo de satélites con sensores que registran datos a distintas resoluciones espaciales, temporales, radiométricas y espectrales permitieron observar la superficie terrestre en forma periódica para complementar los estudios sobre el medio ambiente. Sobre la base de estas herramientas, los objetivos del presente estudio fueron analizarla respuesta espacio-temporal de cuerpos de agua de la Región Pampeana y su posible relación con los eventos extremos de pluviometría.

El área de estudio corresponde a la Región Pampeana, Argentina según los límites definidos por Labraga et al. (2010). Está conformada por las provincias de Buenos Aires, Entre Ríos, noreste de La Pampa, sureste de Córdoba, centro y sudeste de San Luis, sur de Santa Fe y centro-sur de Corrientes (Figura 1). Constituye el paisaje más productivo del país con una superficie aproximada de $613.532 \mathrm{~km}^{2}$ (Labraga et al., 2010). La misma se extiende sobre una zona predominantemente llana con presencia de sierras en el sudoeste (Sistema de Ventania, $\sim 1240 \mathrm{msnm}$ ) y centro (Sistema de Tandilia, 500) de la provincia de Buenos Aires y en el oeste de la región en la provincia de Córdoba (Sierras Pampeanas, $\sim 1668 \mathrm{msnm}$ ).

Dada la vasta extensión espacial del área de estudio, en una primera instancia se la subdividió teniendo en cuenta los distintos regímenes pluviométricos que se detectan en ella. Para ello, se aplicó un análisis de conglomerados sobre datos mensuales de precipitación de 33 estaciones meteorológicas pertenecientes al Servicio Meteorológico Nacional (SMN, Argentina) para el período 1960-2010 (Figura 1). Como resultado se obtuvieron 6 subregiones, a saber: Extremadamente Húmeda (EH), Muy Húmeda (MH), Moderadamente Húmeda (ModH), Húmeda (H), Seca (S) y Muy Seca (MS) (Figura 1). El curso anual de precipitaciones para cada subregión mostró una estacionalidad con picos máximos durante los meses de otoño (marzo-abril) y primavera (octubrenoviembre) para todas ellas. Además, las sub regiones marcaron una estación seca durante el invierno (Figura 2). Una vez realizada la subregionalización, se estudió la ocurrencia y frecuencia de los eventos extremos de precipitación mediante la aplicación del Índice Estandarizado de Precipitación (IEP) y la Transformación de Wavelets Continua. Ambos métodos permitieron realizar el análisis de los eventos secos, húmedos y normales en cada una de las sub regiones. 
Figura 1. Localización de la Región Pampeana según Labragaet al., 2010.

Zonificación de la región pampeana según su régimen pluviométrico (1960-2010).
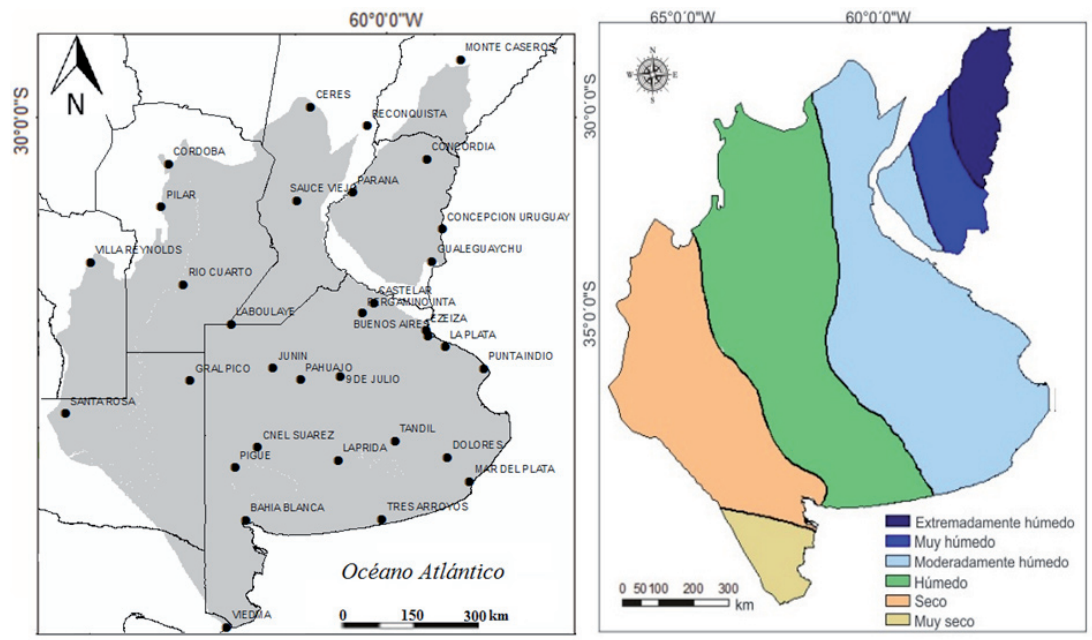

Fuente. Elaboración propia

Figura 2. Evolución anual de precipitación para el período 1960-2010, en cada sub región.

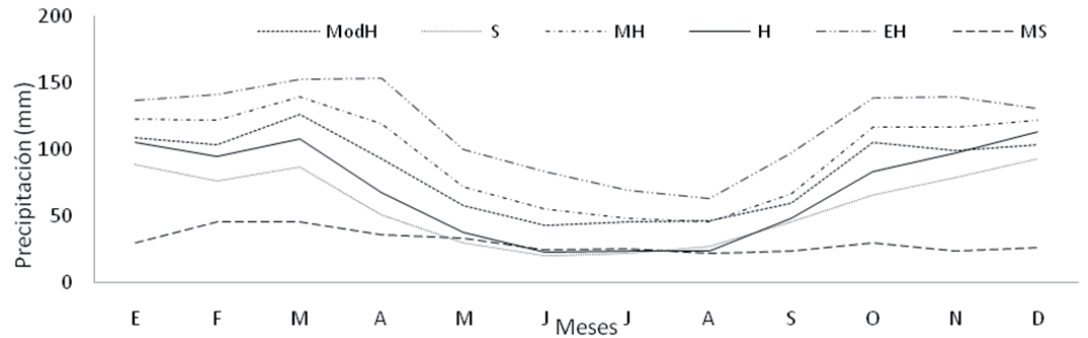

Fuente. Aliaga et al., 2016.

A partir de la determinación de los eventos extremos de precipitación, se procedió a seleccionar como ejemplo un cuerpo de agua perteneciente a cada subregión. Cada uno de ellos fue monitoreado durante eventos extremos de pluviometría con el fin de determinar variaciones en sus características físicas (color, reflectividad, material particulado suspensión) y morfométricas. Para este estudio se utilizaron 45 imágenes satelitales, de las cuales 18 fueron LANDSAT 5 TM, 12 LANDSAT 8 OLI - TIRS y 15 SPOT 5y se descarga- ron del United States Geological Survey (USGS, Estados Unidos) y de la Comisión Nacional de Actividades Espaciales (CONAE, Argentina). Las mismas se procesaron digitalmente para corregirlas geométrica, radiométrica y atmosféricamente. Además, se validó el cálculo del área de los cuerpos de agua con imágenes satelitales LANDSAT (resolución espacial de $30 \mathrm{~m}^{2}$ )y SPOT (resolución espacial de 10 $\mathrm{m}^{2}$ ) utilizando el método no supervisado ISODATA. Esta relación arrojó resultados con un alto nivel de correlación. Al 
separar por sub regiones, se observó que las muy húmedas ( $\mathrm{EH}$ y $\mathrm{MH})$ fueron las que presentaron menor ajuste dado que en ellas se localizan más cuerpos de agua de menor tamaño, haciendo que la sobre-estimación propia del tamaño del píxel de la imagen LANDSAT genere mayores errores en la comparación. A pesar de ello, los resultados fueron altamente significativos y el test de Fisher y el ANOVA no encontraron evidencia estadística de que los valores medios sean distintos, por lo que se consideró que las imágenes LANDSAT fueron una buena herramienta para realizar este estudio.

Las variaciones de la reflectividad manifestaron una relación con el Material Particulado en Suspensión (MPS) y con el color de los cuerpos de agua analizados visualmente con combinaciones de falso color natural (Figura 3). En donde las situaciones fueron de color verde, rojizo o más claro, las firmas espectrales tuvieron mayor porcentaje de reflectividad y el MPS, mayor valor. Se determinó una relación entre los eventos extremos pluviométricos y las respuestas espacio-temporales de los cuerpos de agua en todas las sub regiones. Se destaca que las lagunas que mostraron una menor variación espacial fueron aquellas localizadas en los regímenes más húmedos (EH y MH) en situaciones de eventos normales y húmedos. Las de la región MS y $\mathrm{H}$ fueron las que manifestaron grandes variaciones en relación con la precipitación (Tabla 1). Sin embargo, se considera que hay otros factores que influyen sobre la dinámica de los cuerpos de agua como por ejemplo su profundidad, su función eco-sistémica, el aporte tributario natural o antropogénico, de aguas subterráneas, el relieve, su origen, etc. La estructura y el funcionamiento de las lagunas pampeanas pueden explicarse por su geomorfología, régimen climático, drenajes, suelos y por las modificaciones humanas. Es posible entonces caracterizarlas sintéticamente como lagos de llanura, someros, eutróficos o hipertróficos y con tiempo de permanencia del agua y salinidad altamente variables (Quirós, et al., 2002).

Figura 3. Variación del color en distintos eventos extremos de pluviometría en

1. La Limpia, 2. Blanca, 3. Chascomús, 4. La Picasa, 5. Chasicó y 6. La Petrona.

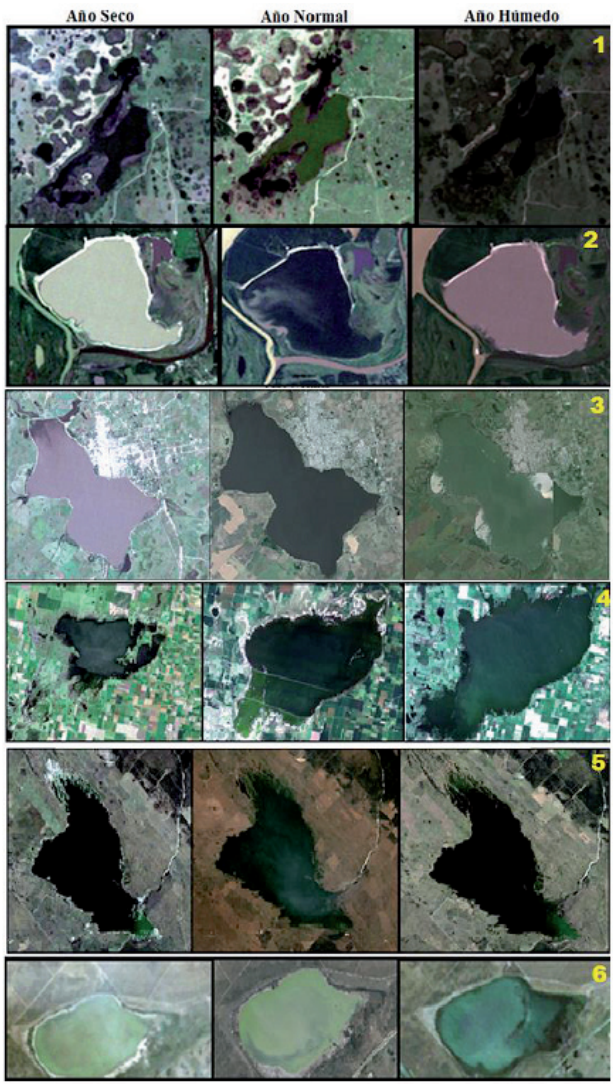

Fuente: Elaboración propia. 
Tabla 1. Variación de los parámetros morfométricos en las lagunas estudiadas. PM. Parámetros Morfométricos, A. Área, P. Perímetro, LMT. Longitud máxima total, OLMT., orientación de la LMT, Amax. Ancho máximo, Amed. Ancho medio, DLC. Desarrollo de línea de costa.

\begin{tabular}{|c|c|c|c|c|}
\hline Laguna & $P M$ & Año Seco & Año Normal & Año Húmedo \\
\hline \multirow{7}{*}{ La Limpia } & $A\left(k^{2}\right)$ & 2,1 & 3 & 3,1 \\
\hline & $\mathbf{P}(\mathrm{km})$ & 12 & 14,8 & 14,9 \\
\hline & LMT (km) & 2,8 & 3,7 & 3,9 \\
\hline & OLMT & NE-SW & NE-SW & NE-SW \\
\hline & Amax (km) & 1,4 & 1,5 & 1,6 \\
\hline & Amed & 0,8 & 0,8 & 0,8 \\
\hline & DLC & 2,3 & 2,4 & 2,4 \\
\hline \multirow{7}{*}{ Blanca } & $\mathrm{A}\left(\mathrm{km}^{2}\right)$ & 5,5 & 5,6 & 5,8 \\
\hline & $P(\mathrm{~km})$ & 11,1 & 11,1 & 11,3 \\
\hline & LMT (km) & 3.7 & 3.6 & 3.7 \\
\hline & OLMT & NW-SE & NE-SE & NW-SE \\
\hline & $\operatorname{Amax}(\mathrm{km})$ & 2,7 & 2,8 & 2,7 \\
\hline & Amed & 1,5 & 1,6 & 1,6 \\
\hline & DLC & 1,3 & 1,3 & 1,3 \\
\hline \multirow{7}{*}{ Chascomús } & $A\left(\mathrm{~km}^{2}\right)$ & 27 & 32,6 & 33,1 \\
\hline & $\mathbf{P}(\mathbf{k m})$ & 26,7 & 30,7 & 38,2 \\
\hline & LMT (km) & 9,4 & 9,2 & 10 \\
\hline & OLMT & $\mathrm{N}-\mathrm{SE}$ & N-SE & $\mathrm{N}-\mathrm{SE}$ \\
\hline & Amax (km) & 4,9 & 4,9 & 5 \\
\hline & Amed & 2,9 & 3,5 & 3,3 \\
\hline & DLC & 1,4 & 1,5 & 1,9 \\
\hline \multirow{7}{*}{ La Picasa } & $A\left(\mathrm{~km}^{2}\right)$ & 109,2 & 211,1 & 386,7 \\
\hline & $\mathrm{P}(\mathrm{km})$ & 81,9 & 77,8 & 139,1 \\
\hline & LMT (km) & 11,7 & 25,3 & 36,3 \\
\hline & OLMT & NW-SE & SW-NE & SW-NE \\
\hline & Amax (km) & 11,1 & 16 & 17,4 \\
\hline & Amed & 9,3 & 8,3 & 10,7 \\
\hline & DLC & 2,2 & 1,5 & 2 \\
\hline \multirow{7}{*}{ Chasicó } & $A\left(\mathrm{~km}^{2}\right)$ & 61,6 & 62,8 & 68,2 \\
\hline & $\mathrm{P}(\mathbf{k m})$ & 42,7 & 42 & 49,5 \\
\hline & LMT (km) & 13,9 & 14 & 15,1 \\
\hline & OLMT & NW-SE & NW-SE & NW-SE \\
\hline & $A \max (\mathrm{km})$ & 7,9 & 8,3 & 8,3 \\
\hline & Amed & 4,4 & 4,5 & 4,5 \\
\hline & DLC & 1,5 & 1,5 & 1,7 \\
\hline \multirow{7}{*}{ La Petrona } & $A\left(\mathrm{~km}^{2}\right)$ & 3,4 & 5,2 & 5,4 \\
\hline & $P(\mathrm{~km})$ & 8,7 & 9,4 & 10,3 \\
\hline & LMT (km) & 3,1 & 3,6 & 3,8 \\
\hline & OLMT & $E-W$ & $E-W$ & E-W \\
\hline & $A \max (\mathrm{km})$ & 1,9 & 2,1 & 2,2 \\
\hline & Amed & 1,1 & 1,4 & 1,4 \\
\hline & DLC & 1,3 & 1,2 & 1,3 \\
\hline
\end{tabular}

Fuente: Elaboración propia.

Por todo lo mencionado, se considera que el conocimiento de la variabilidad de las precipitaciones en la Región Pampeana es una herramienta que podría ayudar a estudios ambientales y aportar información para las políticas de ordenamiento del territorio. Esta variabilidad puede afectar a la población ya sea produciendo inundaciones como sequías que afectan no sólo a las actividades agropecuarias sino también a la calidad de vida de los ciudadanos. Los efectos de la variación de la precipitación pueden intervenir en la agricultura, dado que en las épocas en 
donde las precipitaciones son mayores, favorecen el crecimiento de los cultivos al aumentar la humedad del suelo, al contrario del estrés generado por las sequías (Huber y Trecaman, 2002). Es necesario plantear nuevas alternativas de ordenamiento sustentable con un plan de manejo integral de los recursos hídricos en la región pampeana considerando los diferentes regímenes pluviométricos.

\section{Bibliografía citada}

ALIAGA, V., FERRELli, F., ALBERDI ALGARAÑAZ, E.D., BOHN, V. Y. Y PICCOLO, M. C. (2016). "Distribución y variabilidad de la precipitación en la región pampeana argentina”. Cuadernos de Investigación Geográfica, Universidad de La Rioja, España, Vol. 42 (1), pp. 261-280.
HUBER, A. Y TRECAMAN, R.(2002). "Efectos de la variabilidad interanual de las precipitaciones sobre el desarrollo de plantaciones de Pinus radiata (D. Don) en la zona de los arenales VIII Región, Chile". Bosque, Vol. 23(2), pp.43-49.

LABRAGA, J., BRANDIZI, L. Y LÓPEZ, M.(2010). "Avances en el pronóstico climático de las anomalías de lluvia en la Región Pampeana”. Meteorológica Vol. 36,pp. 59-71.

QUIROS, R., RENELLA, A., BOVERI, M., ROSSO, J Y SOSNOVSKY, A. (2002). "Factores que afectan la estructura y el funcionamiento de las lagunas pampeanas". Ecología Austral Vol. 12, pp. 175-185. 